\title{
The Use of Medical Scribes in Health Care Settings: A Systematic Review and Future Directions
}

\author{
Cameron G. Shultz, PhD, MSW, and Heather L. Holmstrom, MD
}

Background: Electronic health records (EHRs) hold promise to improve productivity, quality, and outcomes; however, using EHRs can be cumbersome, disruptive to workflow, and off-putting to patients and clinicians. One proposed solution to this problem is the use of medical scribes. The purpose of this systematic review is to summarize the literature investigating the effect of medical scribes on health care productivity, quality, and outcomes. Implications for future research are discussed.

Methods: A keyword search of the Cochrane Library, OvidSP Medline database, and Embase database from January 2000 through September 2014 was performed using the terms scribe or scribes in the title or abstract. To ensure no potentially eligible articles were missed, a second search was done using Google Scholar. English-language, peer-reviewed studies assessing the effect of medical scribes on health care productivity, quality, and outcomes were retained. Identified studies were assessed and the findings reported.

Results: Five studies were identified. Three studies assessed scribe use in an emergency department, 1 in a cardiology clinic, and 1 in a urology clinic. Two of 3 studies reported scribes had no effect on patient satisfaction; 2 of 2 reported improved clinician satisfaction; 2 of 3 reported an increase in the number of patients; 2 of 2 reported an increase in the number of relative value units per hour; 1 of 1 reported increased revenue; 3 of 4 reported improved time-related efficiencies; and 1 of 1 reported improved patient-clinician interactions.

Conclusions: Available evidence suggests medical scribes may improve clinician satisfaction, productivity, time-related efficiencies, revenue, and patient-clinician interactions. Because the number of studies is small, and because each study suffered important limitations, confidence in the reliability of the evidence is significantly constrained. Given the nascent state of the science, methodologically rigorous and sufficiently powered studies are greatly needed. (J Am Board Fam Med 2015;28:371-381.)

Keywords: Electronic Health Records; Information Systems; Medical Economics; Medical Scribe; Review, Systematic

Electronic health records (EHRs) are frequently recognized as a promising tool to help improve health care quality, safety, outcomes, and productivity. ${ }^{1-3}$ In the United States (US), the Health Information Technology for Economic and Clinical Health Act of 2009 established incentive programs to promote meaningful use of EHRs within primary care and other health care settings. ${ }^{4}$ As of

This article was externally peer reviewed.

Submitted 5 August 2014; revised 6 November 2014; accepted 12 November 2014.

From the Department of Family Medicine, University of Michigan, Ann Arbor.

Funding: none.

Conflict of interest: none declared.

Corresponding author: Cameron G. Shultz, PhD, MSW, 1018 Fuller St, Ann Arbor, MI 48104-1213 (E-mail: cshultz@med.umich.edu).
2012, 72\% of US office-based physicians described using some type of EHR or electronic medical record system: $40 \%$ described using a basic EHR system, and $24 \%$ reported a fully functional system. ${ }^{5}$ Among US general, acute care hospitals in 2012, 27\% reported using a basic EHR system and $17 \%$ reported a comprehensive system. ${ }^{6}$ By 2019, an estimated $80 \%$ of physicians in large group practices, $65 \%$ in small group practices, and $66 \%$ of all other specialists are expected to have achieved meaningful use. ${ }^{7}$

Emerging evidence indicates there may be important advantages to EHR adoption, including structural- and process-related benefits ${ }^{8}$ and enhanced patient care. ${ }^{9}$ Despite their promise to improve clinic-related efficiencies, recent findings indicate EHRs can, over the short-term, reduce 
productivity while at the same time add to expenses. ${ }^{10}$ While productivity is likely to recover after clinicians and support staff acclimate to the system, ${ }^{10}$ clinician engagement and administrative practice issues remain as commonly identified problems. $^{11}$

Many physicians describe challenges with the current state of the technology: EHRs can be difficult to use, time consuming, inefficient, disruptive to face-to-face encounters with patients, and a hindrance to the clinical documentation process. ${ }^{12-14}$ These challenges may be especially pronounced among those who lack support to help manage the flow of information. ${ }^{13}$ Difficulty associated with the usability of EHRs remains an important source of professional dissatisfaction; early adopters report the technology can at times interfere with communication during visits and patient-clinician eye contact. ${ }^{13,15}$ Evidence suggests some physicians using EHRs may also engage patients in fewer physician-initiated gaze patterns (signaling a lack of attention toward the patient), and that EHR use may contribute to a sense of separation among some patients when the EHR monitor is kept away from the patient's view. ${ }^{16,17}$ In response to concerns like these, a recently published primary care consensus statement concluded that many EHR systems need marked refinement to promote greater patient engagement. ${ }^{18}$

One proposed solution to improve patient engagement and the flow of information while using EHRs during the clinical encounter is the use of medical scribes. While the roles of scribes can vary based on the nuances of a given clinical setting, in general scribes are personnel specifically hired to chart patient-clinician encounters in real time, from the beginning of the encounter to its end. As defined by the Joint Commission:

A scribe is an unlicensed person hired to enter information into the EHR or chart at the direction of a physician or practitioner (Licensed Independent Practitioner, Advanced Practice Registered Nurse or Physician Assistant). It is the Joint Commission's stand that the scribe does not and may not act independently but can document the previously determined physician's or practitioner's dictation and/or activities. ${ }^{19}$

Many personnel types with different levels of training can work as a medical scribe, including nursing, medical students, or individuals whose only medical training is limited to that of being a scribe. Importantly, the identification of a person as a scribe is not dependent on their training per se, but the person's predefined role. If a medical student is learning note-taking skills by documenting clinical encounters under the guidance of a physician in a student-preceptor relationship, then the student in this case is not acting as a medical scribe. If, however, a hired note taker also happens to be a medical student, and the purpose of the student's role in the clinical setting is to document the clinical encounter (and not to receive teaching or mentoring), then the student in this case is a medical scribe.

In some settings medical scribe services may be contractually arranged with an independently operated scribe company, whereas in other settings scribes may be direct employees of the health system or clinic. Likewise, the tasks performed by the scribe can vary from setting to setting. In settings with fully functional EHRs the scribe might actively participate in the clinical encounter, serving as an interface between the EHR and the clinician; for example, the scribe could communicate to the clinician information generated by the EHR such as automatic warnings, prompts, or reminders. In other settings the scribes' role could be essentially invisible, where direct interactions with the clinician or patient are kept to a minimum.

After the scribe's documentation is complete, the clinician must authenticate the scribe's entry via signing and dating/timing. The Joint Commission does not support the use of scribes for entering orders on behalf of the clinician, given the additional risk for error ${ }^{19}$; if, however, the person serving as a scribe also happens to be a licensed health care professional, they could perform duties commensurate with their licensure.

Although reports on the use of medical scribes date back to the mid-1970s and early 1980 s, ${ }^{20-22}$ to our knowledge a summary of the evidence on the topic has never been published. The purpose of this systematic review, therefore, is to summarize the literature investigating the effect of medical scribes on health care productivity, quality, and outcomes.

\section{Methods}

A keyword search of the Cochrane Library, OvidSP Medline database, and Embase database from January 2000 through September 2014 was performed, focusing on articles using scribe or scribes in the title 
or abstract. The cutoff date of January 2000 was chosen based on the Institute of Medicine's conclusion that the use of EHRs before this time was uncommon. ${ }^{1,23}$ After removing duplicative sources, each remaining source was individually screened by means of assessing the title, abstract, and/or the original source document. The following exclusion criteria were applied: publications not in English; sources not focusing on the use of medical scribes in the clinical setting (eg, biblical scribes); conference abstracts; and sources not investigating the effect of medical scribes on health care productivity, quality, or outcomes (eg, narrative descriptions of an existing medical scribe program, commentaries).

To ensure capture of all potentially eligible studies, we performed a second search using advanced search features in Google Scholar. While the details of Google Scholar's search algorithm are proprietary and not known, the engine includes "articles, theses, books, abstracts and court opinions, from academic publishers, professional societies, on-line repositories, universities and other web sites." ${ }^{24}$ The parameters for the advanced Google Scholar search were English-language sources, excluding patents and citations, posted from January 2000 through September 2014 and using scribe or scribes in the title. Each result was individually screened by means of assessing the title, abstract, and/or the original source document. The following exclusion criteria were applied: books; sources not focusing on the use of medical scribes in the clinical setting; conference abstracts; sources not investigating the effect of medical scribes on health care productivity, quality, and/or outcomes; and articles previously identified for inclusion from the database search (Cochrane Library, OvidSP Medline database, and Embase database).

The list of references from each included study was then reviewed to assess for potentially eligible studies not otherwise captured. Likewise, for each included study a forward publication search was performed using the All Databases engine via Thomson Reuters Web of Science (http://apps.webofknowledge.com).

We evaluated the identified sources, and study design, measures, outcomes, and limitations were recorded. Any disagreements were negotiated until $100 \%$ consensus was achieved. Findings were sum- marized, including recommendations for future research.

\section{Results}

In total, 876 sources were identified: 5 from the Cochrane Library, 94 from OvidSP Medline, 142 from Embase, and 635 from Google Scholar. As shown in Figure 1, application of exclusion criteria resulted in 5 studies for this review. Four studies were identified using the database search ${ }^{25-28}$ and 1 through Google Scholar. ${ }^{29}$ No additional studies were identified by searching the included studies' reference lists or the forward publication search.

\section{Overview}

Table 1 summarizes each study's setting and sample, design (including scribe type, when reported), and measured outcomes. Three studies were nonrandomized, static group comparisons, ${ }^{25-27} 1$ was a 2-stage pretest/posttest design with a static group comparison, ${ }^{28}$ and 1 was a simple pretest/posttest design. ${ }^{29}$ Three studies measured scribe use in the emergency department, ${ }^{25,28,29} 1$ in a cardiology clinic, ${ }^{27}$ and 1 in a urology clinic. ${ }^{26}$ Each study setting was affiliated with a larger academic health center, ${ }^{25,26,29}$ health care organization, ${ }^{27}$ or community hospital. ${ }^{28}$

\section{Medical Scribes}

Four of the 5 studies described the type of medical scribes used in the research. ${ }^{25-28}$ Scribe types varied in terms of both training and employment relationship with the clinical setting. In 2 studies the scribes were students (premedical, prenursing, pre-physician assistant, or first-year medical students). ${ }^{26,28}$ In the first, the nature of the employment relationship between the scribe and clinical setting was not clearly specified. The study described a 2-week, nonstandardized training period during which the scribe familiarized themselves with the urology practice site and its documentation practices. ${ }^{26}$ In the second, scribes were contracted through a professional scribe service. Beyond the training offered by the professional scribe service and the scribes' orientation to the emergency department, no specific training information was described. ${ }^{28}$

Among the 2 studies not using students, 1 described obtaining the scribes from a scribe training program operated through the parent medical center, ${ }^{25}$ and the other hired an experienced scribe 
Figure 1. Flow diagram of the search strategy used to identify literature investigating the effect of medical scribes on health care productivity, quality, and outcomes. The database search queried the Cochrane Library, the OvidSP Medline database, and the Embase database from January 2000 through September 2014 for articles using scribe or scribes in the title or abstract. The Google Scholar search queried English-language sources (excluding patents and citations) posted from January 2000 through September 2014 and using scribe or scribes in the title.

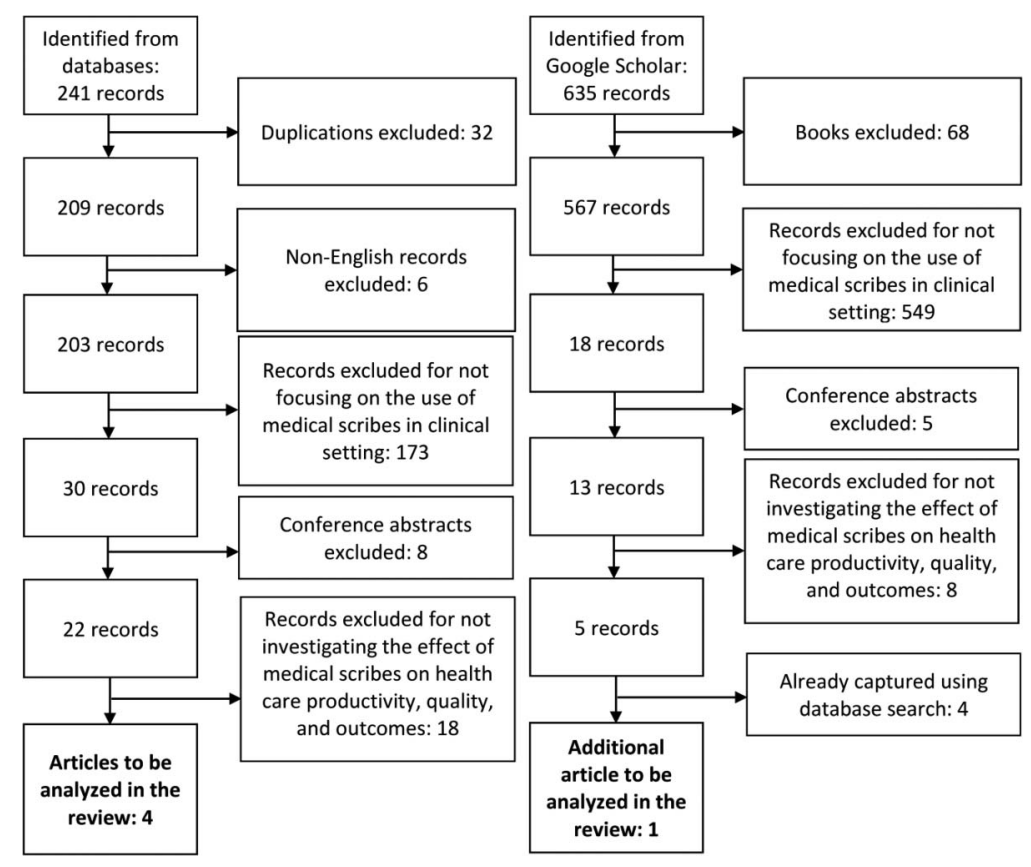

through a professional corporation that provides medical scribing services. ${ }^{27}$ Scribes trained by the medical center met specific prerequisites, including 2 years' clerical experience and familiarity with relevant software packages; the program included 60 hours of training. The experienced scribe from the medical scribing service had been a scribe for 6 years; this person received 3 hours of additional training to learn the procedures and medical issues specific to the cardiology practice site. ${ }^{27}$

Duties performed by medical scribes in the 5 studies are delineated in Table 2. Four studies reported scribes were assigned to work with a single clinician within a given shift ${ }^{25-28} ; 1$ study reported scribes worked with multiple clinicians within a designated area over the course of a single shift. ${ }^{29}$ While the level of specificity in the description of scribe duties varied from study to study, each described the fundamental task of providing documentation services. Two studies, each investigating the use of scribes in an emergency department setting, made specific reference to scribes not entering orders directly into the medical record. ${ }^{28,29}$

\section{Outcomes}

Outcomes associated with the 5 studies are summarized in Table 3. Two of 3 studies reported scribes had no effect on patient satisfaction; 2 of 2 reported improved clinician satisfaction; 2 of 3 reported an increase in the number of patients; 2 of 2 reported an increase in the number of relative value units (RVUs) per hour; 1 of 1 reported increased revenue; 3 of 4 reported improved time-related efficiencies; and 1 of 1 reported improved patientclinician interactions.

\section{Patient Satisfaction}

Three studies measured patient satisfaction, ${ }^{26-28}$ with most measures not reaching the level of statistical significance. Only Bastani et $\mathrm{a}^{28}$ observed a significant improvement, with the postscribe time period rebounding to the level observed before implementing the emergency department's computerized physician order entry system.

\section{Clinician Satisfaction}

Both studies assessing clinician satisfaction reported scribe use had a positive impact. ${ }^{26,29} \mathrm{Com}$ - 
Table 1. Characteristics of English-Language, Peer-Reviewed Studies Assessing the Effect of Medical Scribes on Health Care Productivity, Quality, and Outcomes

\begin{tabular}{|c|c|c|c|}
\hline Article & Setting and Sample & Study Design and Scribe Type & Measured Outcomes \\
\hline Arya et $\mathrm{al}^{25}$ & $\begin{array}{l}\text { - Emergency department within } \\
\text { a single academic medical } \\
\text { center } \\
\text { - } 243 \text { shifts } \\
\text { - } 13 \text { emergency physicians } \\
\text { - Data collected on all adult } \\
\text { ( } \geq 21 \text { years old) patient visits }\end{array}$ & $\begin{array}{l}\text { - Nonrandomized, static-group } \\
\text { comparison study } \\
\text { - Matched design (shifts with and } \\
\text { without scribes) } \\
\text { - Scribes: from preexisting program } \\
\text { operated through the academic } \\
\text { medical center }\end{array}$ & $\begin{array}{l}\text { - RVU/hour } \\
\text { - Patients/hour } \\
\text { - Turnaround time to discharge } \\
\text { (minutes) }\end{array}$ \\
\hline Koshy et $\mathrm{al}^{26}$ & $\begin{array}{l}\text { - Urology clinic within a single } \\
\text { academic medical center } \\
\text { - } 5 \text { urologists; residents } \\
\text { - } 487 \text { patient surveys } \\
\text { - } 55 \text { physician surveys }\end{array}$ & $\begin{array}{l}\text { - Nonrandomized, static-group } \\
\text { comparison study } \\
\text { - Matched design (shifts with and } \\
\text { without scribes) } \\
\text { - Scribes: premedical students or first- } \\
\text { year medical students }\end{array}$ & $\begin{array}{l}\text { - Patient acceptance and } \\
\text { satisfaction } \\
\text { - Physician acceptance and } \\
\text { satisfaction }\end{array}$ \\
\hline Bank et $\mathrm{al}^{27}$ & $\begin{array}{l}\text { - Cardiology clinic within a } \\
\text { large, not-for-profit health } \\
\text { care organization } \\
\text { - } 65 \text { hours of clinic care on } \\
\text { both control and scribe days } \\
\text { - } 4 \text { cardiologists } \\
\text { - } 130 \text { clinic hours } \\
\text { - } 339 \text { patient visits }\end{array}$ & $\begin{array}{l}\text { - Nonrandomized, static-group } \\
\text { comparison study } \\
\text { - Matched design (days with and } \\
\text { without scribes); patient visits on } \\
\text { scribe days were scheduled to be } 25 \% \\
\text { shorter } \\
\text { - Scribe: professional scribe from a } \\
\text { medical scribe service }\end{array}$ & $\begin{array}{l}\text { - Patients seen } \\
\text { - wRVU/hour } \\
\text { - Patient satisfaction } \\
\text { - Physician-patient interaction } \\
\text { - Revenue }\end{array}$ \\
\hline Bastani et $\mathrm{a}^{28}$ & $\begin{array}{l}\text { - Emergency department in a } \\
\text { suburban community hospital } \\
\text { - Patient encounters over the } \\
11 \text {-month study, with } \\
\text { "washout" time between } \\
\text { groups } \\
\text { - Before CPOE, n = 10,578 } \\
\text { - After CPOE and before } \\
\text { scribe, } \mathrm{n}=11,729 \\
\text { - After scribe, } \mathrm{n}=12,609\end{array}$ & $\begin{array}{l}\text { - Nonrandomized, 2-stage } \\
\text { pretest/posttest design (baseline/before } \\
\text { CPOE, after CPOE, and after scribe) } \\
\text { with static-group comparison } \\
\text { - Scribes: premedical, prenursing, and } \\
\text { pre-physician assistant students from a } \\
\text { local 4-year university; employed via a } \\
\text { professional scribe service }\end{array}$ & $\begin{array}{l}\text { - Door-to-room time } \\
\text { - Room-to-doctor time } \\
\text { - Door-to-doctor time } \\
\text { - Doctor-to-disposition time } \\
\text { - Duration of stay for discharged/ } \\
\text { admitted patients } \\
\text { - Patient satisfaction }\end{array}$ \\
\hline Allen et $\mathrm{al}^{29}$ & $\begin{array}{l}\text { - Adult emergency department } \\
\text { within a single academic } \\
\text { medical center } \\
\text { - Patient encounters over the } \\
23 \text {-month study, with } \\
\text { "washout" time between } \\
\text { groups } \\
\text { - } 11 \text {-month periods before and } \\
\text { after scribe } \\
\text { - } 18 \text { residents } \\
\text { - } 8 \text { physician assistants } \\
\text { - } 4 \text { nurse practitioners }\end{array}$ & $\begin{array}{l}\text { - Nonrandomized, pretest/posttest } \\
\text { design (before scribe and after scribe) } \\
\text { - Scribes: not specified }\end{array}$ & $\begin{array}{l}\text { - Patients admitted, discharged, } \\
\text { and left without being seen } \\
\text { - Door-to-triage time } \\
\text { - Door-to-room time } \\
\text { - Door-to-clinician time } \\
\text { - Door-to-disposition time } \\
\text { - Door-to-exit time } \\
\text { - Clinician-to-disposition time } \\
\text { - Disposition-to-exit time } \\
\text { - Room-to-disposition time } \\
\text { - Room-to-exit time } \\
\text { - Clinician satisfaction }\end{array}$ \\
\hline
\end{tabular}

CPOE, computerized physician order entry; RVU, relative value unit; wRVU, work relative value unit.

paring physician shifts without scribes to those with scribes, Koshy et $\mathrm{al}^{26}$ found urologists were more satisfied during office hours with scribes compared with those without. Findings also included a decrease in physicians' reported difficulty with documentation. ${ }^{26}$ Using survey data collected during a single time period after implementation of the scribe program, Allen et $\mathrm{a}^{29}$ found clinicians were generally satisfied with the use of scribes in the emergency department, noting clinicians' belief that scribes saved time with charting, increased time with patients, decreased work-related stress, and increased overall workplace satisfaction.

\section{Productivity}

Three studies measured the effect of scribes on productivity. ${ }^{25,27,29}$ Arya et $\mathrm{al}^{25}$ found that for each $10 \%$ increase in the number of patients with whom a scribe was used, RVUs per hour increased between 0.18 and 0.24 , the latter adjusted for physician assistant utilization. A slight increase in patients per hour (between 0.05 and 0.08 ) was also observed, with the latter again adjusted for physician assistant utilization. Bank et $\mathrm{al}^{27}$ reported work RVUs per hour among cardiologists increased from 3.5 without a scribe to 5.5 with a scribe, and the 


\begin{tabular}{|c|c|}
\hline Study & Duties \\
\hline Arya et $\mathrm{al}^{25}$ & $\begin{array}{l}\text { - Dedicated service to only one emergency department physician per shift } \\
\text { - Create, transcribe, and complete documentation of the patient's medical record } \\
\text { - Communicate laboratory and radiography results to physician in a timely manner } \\
\text { - Complete medical documentation as instructed by physician } \\
\text { - Document time of procedures, calls from physicians, and timeliness of events } \\
\text { - Chart narratives, such as course of events in the emergency department }\end{array}$ \\
\hline Koshy et $\mathrm{al}^{26}$ & $\begin{array}{l}\text { - Dedicated service to a limited number of select urologists, working with only one physician per shift } \\
\text { - Record medical information throughout the patient-physician encounter }\end{array}$ \\
\hline Bank et $\mathrm{al}^{27}$ & $\begin{array}{l}\text { - Dedicated service to a limited number of select cardiologists, working with only one physician per shift } \\
\text { Review records before shift and generate preliminary notes } \\
\text { - Summarize pertinent clinical visits, hospitalizations, and medical history } \\
\text { - Modify progress note and search for additional information at physician's request } \\
\text { - Enter diagnoses, revise problem list, complete follow-up request form, type patient instructions, } \\
\text { document level of service, complete after-visit summary }\end{array}$ \\
\hline Bastani et $\mathrm{al}^{28}$ & $\begin{array}{l}\text { - Dedicated service to only one physician per shift } \\
\text { - Document the initial history, review of systems, and physical examination Record all procedures, } \\
\text { consultations, and reevaluations } \\
\text { - Document electrocardiogram, pulse oximetry, and rhythm strip interpretation } \\
\text { - Detail diagnoses, treatment plans, prescriptions, and discharge/follow-up information } \\
\text { - Track laboratory and imaging tests, keep a task list, cross-check consultations, and follow admission } \\
\text { requests } \\
\text { - Complete all charts before the end of shift }\end{array}$ \\
\hline Allen et $\mathrm{al}^{29}$ & $\begin{array}{l}\text { - Medical documentation services to all clinicians (excluding first-year residents) working in a designated } \\
\text { area } \\
\text { - Provide medical documentation services, including history of present illness, review of systems, physical } \\
\text { exam, lab results, and medical decision making } \\
\text { - Complete charting of the emergency medical record }\end{array}$ \\
\hline
\end{tabular}

number of patients seen per hour increased from 2.2 without a scribe to 3.5 with a scribe. Allen et al's $^{29}$ findings on emergency department productivity were mixed. While a statistically significant change in the number of registered visits per day was not observed, the proportion of patients admitted to the hospital was significantly higher during the postscribe period when compared with the prescribe period: 0.31 versus 0.35 , respectively.

\section{Revenue}

Only 1 study directly investigated revenue generation attributable to the use of scribes. ${ }^{29}$ Revenue was estimated for both direct and indirect (downstream) services, with the average revenue generated per additional patient estimated at $\$ 142$ for direct services and $\$ 2398$ for indirect services. The authors indicated the per-patient increase in revenue was approximately $\$ 2540$, or $\$ 205,740$ when applied to the additional 81 patients seen in the outpatient cardiology clinic.

\section{Time/Efficiency}

Four studies measured the impact of scribes on time-related efficiencies. Of the 3 studies in an emergency department setting, Arya et $\mathrm{al}^{25}$ found scribes had no impact on discharge times; Bastani et $\mathrm{al}^{28}$ found a 13- to 14-minute decrease in the length of stay for admitted and discharged patients, respectively, and a 15-minute improvement in roomto-physician time when compared with a sister institution not using scribes; and while Allen et $\mathrm{al}^{29}$ found an 11-minute decrease in length of stay for discharged patients, a 39-minute increase was observed for admitted patients. Within the urology setting, Bank et $\mathrm{al}^{27}$ reported that direct patient contact time was lower for scribe visits; however, patient-physician interaction without the use of the computer was greater for scribe visits: 6.7 minutes with the scribe versus 1.5 minutes without.

\section{Patient-Clinician Interaction}

One study directly measured the quality of the patient-physician interaction both with and without scribes. ${ }^{27}$ The quality of the visit was assessed by a single rater who scored patient visits with 1 physician using an aggregate measure that assessed the cardiologist's attentiveness; knowledge of the patient's history; use of empathy and open-ended questions; courtesy and respect; repetition of key points to the patient; and clarity of the treatment plan explanation. On a scale from 1 to 10 , with 10 


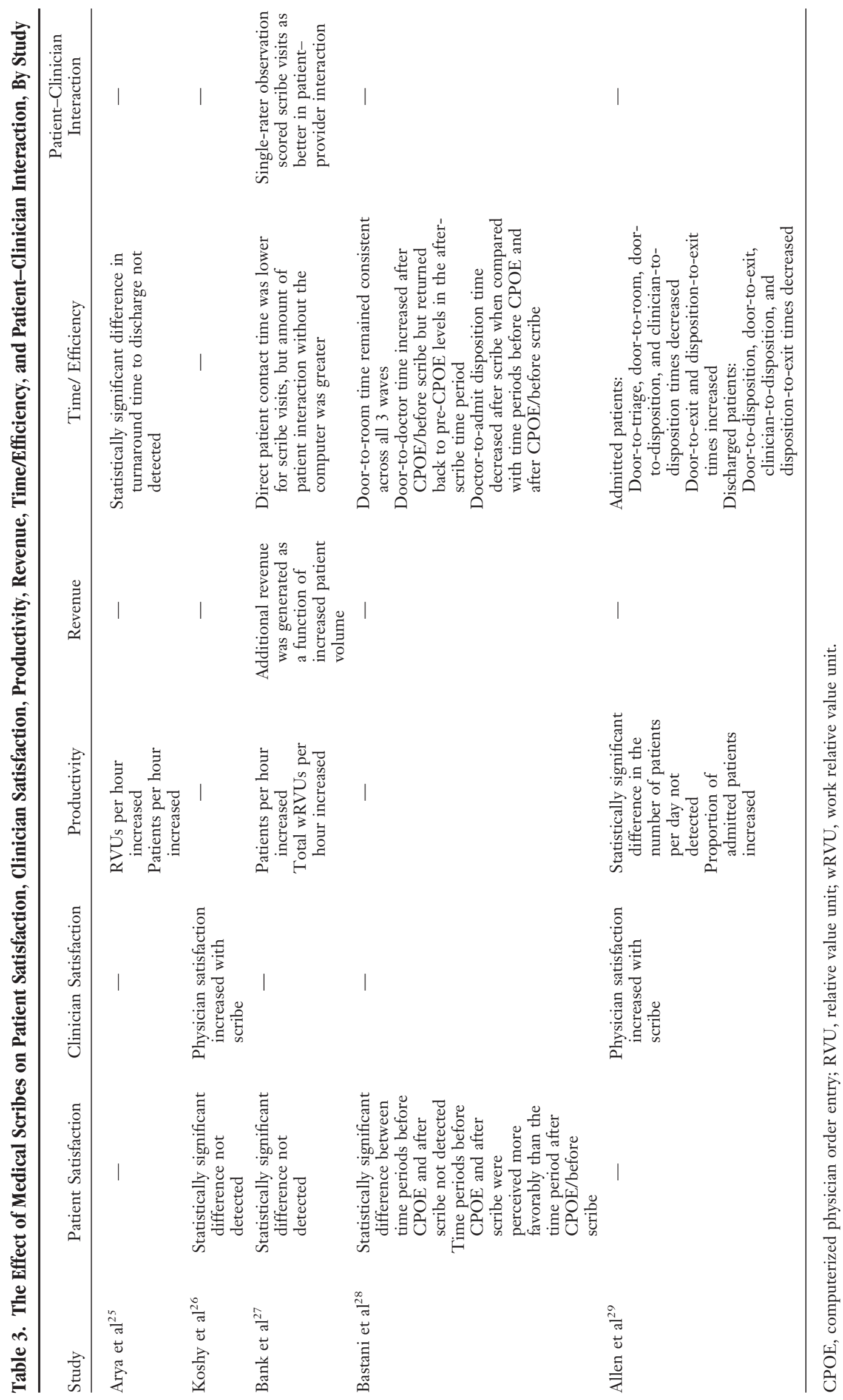


indicating higher quality, visits with a scribe $(\mathrm{n}=$ 14) were scored better than those without a scribe $(\mathrm{n}=9)$ : 9.1 and 7.9, respectively.

\section{Limitations in Study Design}

Important design-related limitations can be broken down into 3 overarching categories: the absence of randomization, limited measures, and shortfalls in reported statistics.

\section{Randomization}

No study randomized scribe use. The lack of randomization seems least problematic in the study by Bank et $\mathrm{al}^{27}$ who assigned equal numbers of cardiologists' clinic hours on scribe and control days. Researchers neither mixed clinicians (ie, only the same 4 cardiologists comprised the scribe and control samples) nor used methods with obvious temporal ordering (ie, scribe days and control days were interspersed). By contrast, Koshy et $\mathrm{al}^{26}$ matched urologists' shifts based on the day of the week. Physicians were stratified by type, such that all resident-patient encounters were assigned to the control group, whereas attending-patient encounters were assigned to either the scribe or control groups. Arya et $\mathrm{al}^{25}$ also used a matched design, pairing emergency physicians' scribe shifts to control shifts within a defined time period. Shifts using the scribes were more likely to occur during the day when patient volume was highest, and some control shifts may have used a scribe for up to $40 \%$ of the shift. Arya et al conceded that the absence of a control for the influence of specific physician assistants may also have influenced physician productivity.

Both Bastani et $\mathrm{al}^{28}$ and Allen et $\mathrm{al}^{29}$ compared outcomes before and after implementation of a scribe program within an emergency department setting. The internal validity of this design is particularly vulnerable to threats from history and maturation, such that many change-producing events other than the experimental intervention could have influenced the observed outcome. Bastani et al describe taking steps to mitigate potential threats, including making no other changes to the staffing model during the study period. They also used a sister institution from the same parent health system as a matched control; only a single comparison-room-to-physician time-was reported, however, and the researchers conceded that the hospital's administration truncated the data collection schedule for reasons external to the study. In contrast to the attempt by Bastani et al to control for extraneous influences, Allen et al reported additional measures implemented during the study period that may have influenced outcomes, including improved clinical guidelines and policies, efforts to enhance communication between admitting and consulting medical services, and EHR support tools. Each of these measures may have affected the observed outcomes.

\section{Measures}

\section{Patient/Clinician Satisfaction}

Four studies used questionnaires to assess patient and/or clinician experiences with medical scribes. ${ }^{26-29}$ Of these, only 1 provided sufficient detail to calculate a response rate $^{29}$; in this study, the response rate was $60 \%$. Of the remaining 3 studies, 1 did not provide detail on the number surveyed, ${ }^{26} 1 \mathrm{did}$ not provide detail on the number returning surveys, ${ }^{27}$ and 1 provided detail on neither the number surveyed nor the number returned. ${ }^{28}$ In the absence of information on both the numerator and the denominator, the representativeness of responses cannot be assessed.

Three studies used survey instruments created specifically for the study, ${ }^{26,27,29}$ and 1 used Press Ganey instruments. ${ }^{28}$ The content of the Press Ganey instruments was not provided; rather, only percentile rankings for the emergency department and its physicians' were given. By contrast, the studies creating their own instruments provided specific detail regarding survey content; 1 study provided the survey's questions word for word. ${ }^{29}$ In the absence of validated instrumentation and/or adequate description regarding the surveys' content, the reliability and internal consistency of the instruments cannot be fully assessed.

\section{Financial Impact/Revenue}

While each study discussed to a greater or lesser degree the potential financial implications of using scribes, only 1 study sought to measure financial impacts straightaway. ${ }^{27}$ In their estimate of indirect returns, Bank et $\mathrm{al}^{27}$ included all cardiovascularrelated revenue generated within 2 months after the patient visit, attributing $100 \%$ of subsequent care to the original encounter. As they suggested, this assumption may be too generous and thus overestimate the true parameter. 
Table 4. Strength of Recommendation Taxonomy: Key Recommendations on the Use of Medical Scribes

\begin{tabular}{|c|c|c|}
\hline Practice Recommendation & Evidence Rating* & References \\
\hline $\begin{array}{l}\text { 1. There is insufficient high-quality evidence to support the claim that medical scribes affect } \\
\text { patient satisfaction. }\end{array}$ & B & $26-28$ \\
\hline $\begin{array}{l}\text { 2. There is insufficient high-quality evidence to support the claim that medical scribes affect } \\
\text { physician satisfaction. }\end{array}$ & B & 26,29 \\
\hline $\begin{array}{l}\text { 3. There is insufficient high-quality evidence to support the claim that medical scribes affect } \\
\text { physician productivity. }\end{array}$ & B & $25,27,29$ \\
\hline $\begin{array}{l}\text { 4. There is insufficient high-quality evidence to support the claim that medical scribes affect } \\
\text { revenue. }\end{array}$ & B & 27 \\
\hline $\begin{array}{l}\text { 5. There is insufficient high-quality evidence to support the claim that medical scribes affect } \\
\text { time-related efficiencies. }\end{array}$ & B & $25,27-29$ \\
\hline $\begin{array}{l}\text { 6. There is insufficient high-quality evidence to support the claim that medical scribes affect } \\
\text { the quality of the patient-clinician interaction. }\end{array}$ & B & 27 \\
\hline
\end{tabular}

*A, recommendation based on consistent and good-quality, patient-oriented evidence; B, recommendation based on inconsistent or limited-quality, patient-oriented evidence; C, recommendation based on consensus, usual practice, expert opinion, disease-oriented evidence, and case series for studies of diagnosis, treatment, prevention, or screening. See Ebell et al ${ }^{30}$ for more information about the strength of recommendation taxonomy evidence rating system.

\section{Patient-Clinician Interaction}

The study by Bank et $\mathrm{al}^{27}$ was also the only one that directly measured the impact of scribes on the timing and quality of the patient-physician interaction. They reported the cardiologist spent more time directly interacting with patients when using the scribe, and visits with the scribe were rated better in terms of interpersonal quality; however, the subsample of patients used for this analysis was very small $(\mathrm{n}=23)$, included only a single cardiologist, and quality scores were generated by a single evaluator.

\section{Reported Statistics}

While each study described findings through the use of $P$ values, only 2 reported confidence intervals $^{25,27}$ and none reported effect sizes. While $P$ values indicate the significance of the results, they communicate little to nothing about the precision of the estimate or its magnitude.

Confidence intervals, based on a predefined probability level, provide a range of values around the statistic, with the width of the interval conveying information about the statistic's precision. Confidence intervals are especially important in studies with small sample sizes, where the interval itself is more likely to be large. In the study by Bank et $\mathrm{al}^{27}$ the confidence intervals for the measures assessing the quality of the patient-cardiologist interaction $(n=23)$ are large enough that they overlap a good deal. While reaching the threshold of statistical significance, the overlap suggests the finding may be neither very precise nor clinically relevant.

Because studies with large samples can identify extremely small changes, the $P$ value alone cannot determine the importance of a given finding. Effect sizes are needed to communicate the magnitude of an observation. Effect sizes help convey to the reader the substantive significance (as opposed to the statistical significance) of a given research finding. In the 2 studies with large samples from an emergency department, ${ }^{28,29}$ the reporting of standardized effect sizes would have helped readers determine whether the change of several minutesover an encounter lasting many hours-is important, as well as enable readers to more easily make comparisons between studies.

\section{Discussion}

As EHRs continue to be integrated within health care settings both large and small, policy makers, health care administrators, and clinicians will need new tools to improve productivity, quality, and outcomes. Current evidence suggests medical scribes may improve clinician satisfaction, productivity, time-related efficiencies, revenue, and patient-clinician interactions; however, because the number of peer-reviewed studies is small, the quality of research is limited, and some findings were not consistent, confidence in the reliability of outcomes is significantly constrained. Recommendations based on the evidence reported in this review are delineated in Table 4. 


\section{Implications for Future Research}

More well-designed and sufficiently powered studies in a variety of practice settings are needed. Given that the majority of physician office visits in the US are in the primary care setting, ${ }^{31}$ research investigating the use of medical scribes within primary care are especially warranted.

Informed by the 5 studies included in this review, the following list outlines several suggestions to help move the research on medical scribes forward:

- Use methods that randomize study and control groups; this could include both who uses the scribes and when the scribes are used.

- Identify how scribe type (eg, training, educational background, experience level, demographic characteristics, employment relationship with the health care setting) affects outcomes.

- Use and/or develop validated measures (eg, satisfaction instruments specific to using medical scribes).

- Report significance levels, confidence intervals, and effect sizes.

- Use qualitative and/or mixed-methods research to develop a richer description of stakeholders' experiences.

- Model revenue and costs using both conservative and liberal criteria/assumptions, thus creating high and low estimates.

- Investigate scribe use in settings operating under different payment systems/models (eg, fee for service, pay for performance, bundled payment).

- Examine the long-term sustainability of scribe use, such as the effects of increased workload over time or whether a setting's existing systems/staff/processes can manage the increased throughput over time.

- Use (or develop) methods/instruments that can capture nuanced features of the patient-clinician interaction (eg, Davis Observation Code, ${ }^{32}$ Roter Interaction Analysis System, ${ }^{33}$ Comprehensive Analysis of the Structure of Encounters System $\left.^{34}\right)$.

\section{Limitations}

This systematic review has several limitations. First, while efforts were made to identify and include all eligible studies, some studies may have been missed. Second, this review included only peer-reviewed studies investigating the effect of medical scribes on health care productivity, quality, and outcomes. While beyond the scope of this review, some sources not included may contain valuable lessons regarding how to successfully implement a scribe program. Third, given the relative dearth of research investigating the use of medical scribes, findings reported in this review may be proven incorrect as more research on the topic is published. Indeed, it is our hope that this review spurs more methodologically rigorous research, thus improving the quality of evidence on the topic.

\section{Conclusion}

Existing evidence on the use of medical scribes is very limited. More research is needed to expand our understanding of how scribes may benefit-or hinder-health care productivity, quality, and outcomes. Those considering the use of scribes should exercise caution, developing clearly defined and empirically derived measures so that the success of the program can be objectively assessed. Performing small-scale studies before widespread implementation would help to mitigate potential risks.

\section{References}

1. Institute of Medicine, Committee on Patient Safety and Health Information Technology. Key capabilities of an electronic health record system. Washington, DC: National Academies Press; 2003.

2. HealthIT.gov. Benefits of electronic health records (EHRs). Available from: http://www.healthit.gov/ providers-professionals/benefits-electronic-healthrecords-ehrs. Accessed July 1, 2014.

3. Institute of Medicine, Committee on Patient Safety and Health Information Technology. Health IT and patient safety: building safer systems for better care. Washington, DC: National Academies Press; 2012.

4. Blumenthal D. Wiring the health system-origins and provisions of a new federal program. N Engl J Med 2011;365:2323-9.

5. Hsiao CJ, Hing E, Ashman J. Trends in electronic health record system use among office-based physicians: United States, 2007-2012. Natl Health Stat Rep 2014;20:1-18.

6. DesRoches CM, Charles D, Furukawa MF, et al. Adoption of electronic health records grows rapidly, but fewer than half of US hospitals had at least a basic system in 2012. Health Aff 2013;32:1478-85.

7. Blavin FE, Buntin MB. Forecasting the use of electronic health records: an expert opinion approach. Medicare Medicaid Res Rev 2013;3:E1-16.

8. Holroyd-Leduc JM, Lorenzetti D, Straus SE, Sykes L, Quan H. The impact of the electronic medical record on structure, process, and outcomes within 
primary care: a systematic review of the evidence. J Am Med Inform Assoc 2011;18:732-7.

9. King J, Patel V, Jamoom EW, Furukawa MF. Clinical benefits of electronic health record use: national findings. Health Serv Res 2014;49(1 Pt 2):392-404.

10. Fleming NS, Becker ER, Culler SD, et al. The impact of electronic health records on workflow and financial measures in primary care practices. Health Serv Res 2014;49(1 Pt 2):405-20.

11. Heisey-Grove D, Danehy LN, Consolazio M, Lynch K, Mostashari F. A national study of challenges to electronic health record adoption and meaningful use. Med Care 2014;52:144-8.

12. Boonstra A, Broekhuis M. Barriers to the acceptance of electronic medical records by physicians from systematic review to taxonomy and interventions. BMC Health Serv Res 2010;10:1-17.

13. Friedberg MW, Chen PG, Van Busum KR, et al. Research report. Factors affecting physician professional satisfaction and their implications for patient care, health systems, and health policy. Santa Monica, CA: Rand Corporation; 2013. Available from: http:// www.rand.org/content/dam/rand/pubs/research_ reports/RR400/RR439/RAND_RR439.pdf. Accessed July 1, 2014.

14. Menachemi N, Collum TH. Benefits and drawbacks of electronic health record systems. Risk Manag Healthc Policy 2011;4:47-55.

15. Makam AN, Lanham HJ, Batchelor K, et al. The good, the bad and the early adopters: providers' attitudes about a common, commercial EHR. J Eval Clin Pract 2014;20:36-42.

16. Montague E, Asan O. Dynamic modeling of patient and physician eye gaze to understand the effects of electronic health records on doctor-patient communication and attention. Int J Med Inform 2014;83: 225-34.

17. Asan O, Montague E. Technology-mediated information sharing between patients and clinicians in primary care encounters. Behav Inf Technol 2014; 33:259-70.

18. Krist AH, Beasley JW, Crosson JC, et al. Electronic health record functionality needed to better support primary care. J Am Med Inform Assoc 2014;21:764-71.

19. The Joint Commission. Use of unlicensed persons acting as scribes. Revised July 12, 2012. Available from: http://www.jointcommission.org/mobile/ standards_information/jcfaqdetails.aspx? Standards FAQId $=426 \&$ StandardsFAQChapterId $=66$. Accessed July 2, 2014.

20. Witt RC, Haedtler DR. Nurse-scribe system saves time in the emergency department. J Emerg Nurs $1975 ; 1: 23-7$.
21. Hixon JR. Scribe system works like a charm in Sarasota ED. Emerg Dep News 1981;3:4.

22. Allred RJ, Ewer S. Improved emergency department patient flow: five years of experience with a scribe system. Ann Emerg Med 1983;12:162-3.

23. Institute of Medicine (US). Crossing the quality chasm: a new health system for the 21 st century. Washington, DC: National Academies Press; 2001.

24. Google. Google Scholar [About page]. Available from: http://scholar.google.com/intl/en-US/scholar/ about.html. Accessed September 9, 2014.

25. Arya R, Salovich DM, Ohman-Strickland P, Merlin MA. Impact of scribes on performance indicators in the emergency department. Acad Emerg Med 2010; 17:490-4.

26. Koshy S, Feustel PJ, Hong M, Kogan BA. Scribes in an ambulatory urology practice: patient and physician satisfaction. J Urol 2010;184:258-62.

27. Bank AJ, Obetz C, Konrardy A, et al. Impact of scribes on patient interaction, productivity, and revenue in a cardiology clinic: a prospective study. Clinicoecon Outcomes Res 2013;5:399-406.

28. Bastani A, Shaqiri B, Palomba K, Bananno D, Anderson $W$. An ED scribe program is able to improve throughput time and patient satisfaction. Am J Emerg Med 2014;32:399-402.

29. Allen B, Banapoor B, Weeks E, Payton T. An assessment of emergency department throughput and provider satisfaction after the implementation of a scribe program. Adv Emerg Med. 2014;2014: 517319.

30. Ebell MH, Siwek J, Weiss BD, et al. Strength of recommendation taxonomy (SORT): a patient-centered approach to grading evidence in the medical literature. J Am Board Fam Pract 2004;17:59-67.

31. Centers for Disease Control \& Prevention, National Center for Health Statistics. National ambulatory medical care survey: 2010 summary tables. Available from: http://www.cdc.gov/nchs/data/ahcd/namcs_ summary/2010_namcs_web_tables.pdf. Accessed October 17, 2014.

32. Callahan EJ, Bertakis KD. Development and validation of the Davis Observation Code. Fam Med 1991; 23:19-24.

33. Roter D, Larson S. The Roter interaction analysis system (RIAS): utility and flexibility for analysis of medical interactions. Patient Educ Couns 2002;46: 243-51.

34. Laws MB, Taubin T, Bezreh T, Lee Y, Beach MC, Wilson IB. Problems and processes in medical encounters: the cases method of dialogue analysis. $\mathrm{Pa}-$ tient Educ Couns 2013;91:192-9. 